\title{
AFFECTIVE-COGNITIVE DIFFERENTIATION AND INTEGRITY AS A DISPOSITIONAL FACTOR IN PERSONALITY AND BEHAVIORAL DISORDERS
}

\author{
Elena T. Sokolova \\ Lomonosov Moscow State University \\ Moscow, Russia
}

The article describes the development of an integrative bio-psycho-social model of personality disorders. This model is based on the interconnection of intellect, self-regulation, self-identity, and social relationships. The prognostic value of the category of "affective-cognitive style" is estimated on the grounds of a meta-analysis of various empirical studies and theoretical models. The article discusses the results of clinical and experimental studies that specify the functions of cognitive differentiation and integrity and of symbolic mediation and reflection in the regulation of the content, emotional valence, temporal stability, and spatial organization of intrapsychic representations of self and interpersonal relationships, as well as the systemic organization of defense and coping operations.

Keywords: Affective-cognitive style as theoretical construct, systemic differentiation\ integration, Vygotsky's methodological paradigm, clinical, experimental studies, personality disorders.

The development of any system can be comprehended in terms of differentiation and integration, which imply the growth of the system's complexity and the degree of specialization and segregation of its subsystems, as well as their interaction (horizontal and vertical). Differentiation and integration secure the cohesiveness of the system as a whole. Pathological processes of any origin lead to structural and functional reorganization of the system along with its substructures. Illness simplifies microstructures, blurs the borders of subsystems (degrades their articulation), and neutralizes qualitative differences among them by making them even; as a result it impoverishes the system functionally and lessens the quality of adaptation. Another consequence of pathological development is a reduction in the number of bonds inside and outside the sys- 
tem, which damages the plasticity, the stability, and the continuity of the whole system (Chuprikova, 2007; Levin, 1935; Sokolova, 1995; Vygotsky, 1956, 1982; Werner, Kaplan, 1963; Witkin, Lewis, Hertzman et al., 1954; Witkin \& Goodenough, 1981).

As an example, let's examine the ontogeny of the system of selfidentity, where interpersonal communication between a child and an adult evokes the "need" for a special "organ" of self-regulation - for selfdefense against the fear of absorption (annihilation) or against the diffuse "mergence" in the growing complexity of relationships with people. The adult becomes the "significant other," who evokes in the child a new specific need and a new circle of life tasks: to "build" oneself (defining self as distinct from the other), to mark out the borders of one's personal self, and to defend one's autonomous existence - and at the same time to preserve one's emotional bond with other people, recasting the feeling of emotional dependence into the feeling of community, of kindred spirits. The "making" of identity is inseparable from the dialectical unity of processes of differentiation and integration, exercised through vertical hierarchization as well as through the integration, assemblage, and harmonization of horizontally coexisting structures (subpersonalities, types of identities, situational identifications, facade self-representations, deep selfhood, etc.). Therefore one grows in integration, self-consistency, inner continuity of self-identity, and along with the feeling of personal autonomy and individuality one develops an ability to experience oneself as part of different types of social communities.

\section{Examination of Theories and of Trends in Experimental Research}

In order to understand the history of the issue it is helpful to outline the ideas of authors who have emphasized the interrelationship of both problems of self-identity, self-regulation, and the development of individuality and overcoming the conflict of urges and intentions (quasineeds) that arise from the interaction of self and environment (field) (Levin, 1935; Witkin, Lewis, Hertzman et al., 1954). In their theoretical and empirical investigations these authors and their disciples were the first to note the importance of the divergence of two types of self-regulation in the course of individual development: the inferior, instinctive, and largely consciously uncontrollable "defenses" as opposed to the 
"controls" - the products of the conscious, social-cognitive conditioning and development of the individuality of the self (Hartmann, 1951, Rapaport, 1951). The defense mechanisms per se were regarded as a limited group of the relatively "primitive" operations subserving the ego in the conflict of instinctive urges. It is assumed that in contrast to them the mechanisms of control (or self-control) are generated by the conflictfree sphere of the ego (Hartmann, 1951) and can be used for perception, evaluation, adjustment to reality - not only without damage to the self but actually taking into account its "inner" individual characteristics. These characteristics are viewed as sui generis mediators, go-betweens in an individual's problem solving: how to balance the inner demands of one's individual intentionality with "pressures" coming from the outer world, from social conditions, and from the interpersonal environment. Psychological survival and adjustment to the social environment are achieved not so much by primitive and infantile means (defensive ignoring and unconscious distortions) but, quite differently and more maturely, by active, conscious efforts to perceive precisely, to explore, to categorize. The further development of this approach led to theoretical and empirical studies of "cognitive controls" and coping mechanisms and their more or less complex integral patterns, which constitute the "style of self-regulation" along with the defense mechanisms. These were the origins of the trend to understand cognitive style as an individual adjustment system of self-control and self-regulation that is developed by the structure of the self in interaction with the social environment and then becomes a mediator itself and determines all the diversity of relationships of the self with significant social environments.

Generated by the interaction of ideas from psychoanalysis, cognitive psychology, developmental psychology, personology, and gestalt psychology, these new theoretical guidelines ("New Look") became a catalyst for the development of a new research paradigm. In the 1950s and 1960s Witkin summarized the results of his 20 years' research on individual differences of perception in extreme environments and gave compelling experimental proofs that cognitive style (the degree of field dependence vs. autonomy and differentiation) corresponds to the type of the whole personality organization, including self-esteem, defenses, and interpersonal attitudes. This paradigm allowed Witkin to view cognitive style as an operational indicator of one of the most generalized characteristics of the systemic organization of personality - the "globality" vs 
the analyticity of its cognitive style (including normal and pathological neuropsychological mechanisms) (Witkin, Lewis, Hertzman et al., 1954). My colleagues and I started our own research on the role of cognitive style as a psychological mechanism for creating "distortions" of selfconsciousness in abnormalities of personality (Sokolova, 1976, 1989) by specifying and theoretically deepening Witkin's idea.

To explain the premise and the design and results of further empirical studies, it is necessary to give a detailed theoretical and empirical definition of the construct of self-identity, as it was one of the central concepts in our research. Let's remember the insights of L.S. Vygotsky on the systemic character of mental development and disintegration and set up some dimensions for the theoretical examination of the issue. The ontogeny of self-identity is a journey from a fragmented, situational, partial, "fractional" self-image to a cohesive and generalized one, from emotionally unstable, affectively charged, and undifferentiated representations of the self and the other to a differentiated, elaborate, and cognitively and emotionally balanced system that is able to organize and "withhold" contradictory and ambivalent experiences. In the course of development, this system becomes increasingly independent of the immediate effects of satisfaction and frustration and of affective oppositions of good and bad. In other words, the development of self-identity can be understood as the growing differentiation of situational identifications from the immediate influence of affects to the advanced mechanisms of self-regulation, which is able to provide the whole system with increasing stability ("constancy"), integrity, and coherence. We can further conclude that the key factor in normal and abnormal functioning is the level of the self-regulation mechanisms. Thus, the "primitive level" of defense mechanisms is typical for borderline personality organization and cannot ensure the stability and integrity of the self faced with frustrations in interpersonal interactions.

The value of the concepts of field dependence and low cognitive differentiation for understanding the development and disintegration of self-identity can be seen in the context of Vygotsky's systemic theory of development. In ontogeny these qualities of the structural and functional organization of identity determine the pattern of interplay of various psychic processes, while in illness they determine the modification of connections and relationships of psychic processes ("subsystems") because of their disintegration in the malignantly changed "social situa- 
tion of development." The most general logic of the development of systems suggests some progression from a conglomerate, undifferentiated, conjoint solidity to differentiation and formation of the clearly defined boundaries of subsystems as a necessary condition for their interaction and further integration into a coherent whole. Vygotsky pointed at the necessity of taking into account the quality of the relationships between affect and intellect as a criterion for individual personality development and virtually suggested the structure-functional model of psychopathology. "In a sense," he writes, "there exists functional equivalence between a high level of personality differentiation and personal flexibility in definite situations and tasks" (Vygotsky, 1983, p. 241). In his theory of the disintegration of concepts in schizophrenia Vygotsky develops the idea of a correlation between the disintegration of the conceptual system (up to the primitive levels of complexes and syncretisms) and the qualitatively different level of relationships not only between affective and cognitive processes but also in the whole system of relations of the self to reality. According to Vygotsky, "In schizophrenia... complex systems dissolve, the affects return to their initial primitive state, lose their connection with thinking. ... The affects begin to change [a person's] thinking. His thinking is a thinking that serves emotional interests and needs" (1982, p. 126). And "in schizophrenia changes in personality and perception of reality result directly from the regression of thinking from the level of concepts to the level of complexes" (1956, p. 494). One can assume that the dissolution of concepts to the primitive stages of complexes and syncretisms - that is, the shift of the whole cognitive system to the genetically earlier and more "primitive" level of functioning - creates those essentially new relationships between cognition and motivation, perception and attitude, that correspond to the field-dependent and undifferentiated affective-cognitive style. In this context the analytical "dimensions" of style can be understood as indicators of balance and the quality of the relationships between "natural," impulsive, sensory-motor, affective-sensuous motivational processes on the one side and culturally mediated, rational, and reflexive processes on the other. These relationships determine the systemic formation and the functioning of self-identity, the level of cognitive mediation (and, in this sense, of "cultural" maturity) of defensive strategies and processes of reality control, the quality of reality testing in the sense of its cognitive acquisition, the intuitive "grasping" of meaning, and the insightful 
and empathic understanding of other people. Thus, field dependence and low differentiation coincide with the situational level of generalization, with a deficit of the ability to symbolize, literality, exactness of representational thinking, confinement within the limits of a particular situation, difficulties in understanding metaphors (in other words, narrow-mindedness in a given situation), and a deficit of creative imagination and empathy, which resembles the phenomena of "mechanistic," "operational" thinking as defined by French psychoanalysts (Marty \& M'Uzan, 2000).

Similar regularities were theoretically predicted, explained, and repeatedly confirmed in our studies. We obtained reliable data on the correlation of low cognitive differentiation with instability of self-image, diffused self-other boundaries, manipulative communication strategies, and a primitively sensuous level of defense operations, which blur social perception and cause biased distortions, prejudices, and loss of distinct orientation in the world of interpersonal relationships.

According to our model, primary disorders of self-identity (instability, disintegration, "diffusion") together with secondary compensatory defense structures (a predominance of archaic narcissistic processes) can be described as "poles" of the affective-cognitive style. To define the level of the structural organization of self-identity we have used two qualities of mental systemic organization - a low level of differentiation of boundaries of mental subsystems, including their poor clarity and accuracy (articulation), and field dependence. These psychological mechanisms are responsible for structural disintegration, the temporal instability of self-attitude, and the poorly functioning autonomy of selfesteem. With our meta-analysis as well as many years of research on the so-called distortions of self-consciousness and their relationship to one's personal cognitive style (Sokolova, 1989, 1995; Sokolova, Burlakova, \& Leontiu, 2001, 2002; Sokolova \& Iljina, 2000; Sokolova \& Korshunova, 2007; Sokolova \& Sotnikova, 2006a), we've been able to specify the role of the affective-cognitive style as the psychological predictor of the disintegration of the structure and the functions of self-identity in borderline and narcissistic personality disorders, to describe persistent "distortions" of self-image on the bodily and categorical levels of selfconsciousness in comorbid diseases - chronic neuroses, depression, hypochondria, food addiction, and suicide - and to find equivalent structures of self-consciousness in female prostitutes, with their promiscuity 
and high victimhood, because of insufficiently defined, blurred, and hence accessible-for-intrusion borders of the self.

\section{Summary of Research}

Our research paradigm was developed on the basis of such psychological phenomena as "tolerance for ambiguity" (Adorno, FrenkelBrunswik, Levinson, \& Sanford, 1950; Sokolova, 1976), which was modeled in experimental settings by varying the degree of physical, semantic, and conceptual ambiguity. The standard experimental scheme consisted of the Embedded Figures Test, the scale of articulation by Witkin (Witkin, Lewis, Hertzman et al., 1954; Witkin \& Goodenough, 1981); the Rorschach Test and the Thematic Apperception Test with scales of affectivecognitive differentiation/integration by Blatt (Blatt, 1990, Blatt \& Lerner 1983); mutuality (Urist, 1977), hostility (Elizur, 1949, Katko, Gregory, Meyer, Mihura, \& Bombel, 2009); the test of body-field perceptual differentiation by (Fischer \& Cleveland, 1968) and other specific tests.

According to the results of our studies, patients at the pole of overdependence show (with certain individual variations) a generalized tendency for global psychological overdependence; difficulty in "distinguishing one's self from the field," including equating one's own self-esteem with the appraisals of significant others ("echo self-esteem"); temporal instability in the system of self-estimations, together with their insufficient generalization and difficulty in integrating negative and positive selfestimations into a cohesive and consistent self-image; a predominance of isolated and poorly structured sensory-motor and sensuous-bodily (vs categorical) levels of self-image; a low tolerance for stress induced by a failure or a criticism (high stress accessibility and weakness of the borders of the self); and a tendency toward negative self-attitude and toward self-rejection.

Their defense structures are characterized by a low level of differentiation, specialization, and cognitive mediation ("primitive defenses" of global action, different variations of sensuous-affective "saturation," and motor acting out), and, therefore, they have limited abilities to "translate" unconscious into categorical structures and to designate, symbolize, and control them consciously. Their relationships with significant others can be maintained exclusively by means of intrapsychic and interpersonal manipulations, which, in this sense, become the behavioral equivalent 
of primitive defense operations for "mastering" and control of affects, generated by conflict between yearning for symbiotic dependence and failure to gain independence and autonomy.

\section{Experimental Studies of Gender- and Body-Identity Disorders}

Corporeality itself may become one's preferential and highly biased interest, one's core of self-attitude, far exceeding interest in other aspects of the self and in other people; such an interest is typical for patients with narcissistic personality disorder. The inner inconsistency of body representations (a consequence of the splitting of sensory and symbolic levels of self-consciousness along with situational thinking) causes polarity in the emotional attitude to one's bodily life, which extends from haughty exhibitionism and perfectionism to a kind of bodily masochism, extremism, and "auto-terrorism." This attitude leads to exaggeration, almost caricature, with the help of which those with a narcissistic personality try to achieve and maintain the attributes of an ideal body but fail and then sadistically punish themselves. The specificity of narcissistic self-identity as a whole, with its splitting, fragmentariness, predominance of unrealistic idolization / devaluation, and impulsive acting out, is reflected in the perception of one's physical and gendered self.

A hypothesis of how two parameters of cognitive style (dependence / autonomy and degree of cognitive differentiation) influence the structure and the character of gender-identity functioning was tested by Sokolova, Burlakova, and Leontiu $(2001,2002)$. According to the results, the balance of dependence / autonomy and degree of differentiation determines whether differentiation / integrity of situational self-images and patterns of self-other relationships develop into a coherent and intrinsically consistent gender identity. These data agree with the results of previous studies that confirmed the correlation of low cognitive differentiation and field dependence with a relatively persistent symptom complex-defective structures of self-consciousness, instability of physical self-image as influenced by changing states of frustration / satisfaction, a low level of cognitive equipment for defense operations, and, therefore, high stress accessibility and high permeability of self-boundaries in patients with food addictions and promiscuous behavior (Sokolova, 1989; Sokolova \& Iljina, 2000). 
Nowadays, with the accelerated growth of the market for services and products that allow modeling and transforming one's appearance at will, when the body becomes a commodity to sell and the expectation is that the value of the body can and should be heightened in every possible way, aesthetic surgery is used along with other innovative technologies to satisfy needs that "saturate" public self-image. And this is not a question of striving for self-development; on the contrary, it is an obsessive, irrational desire to get rid of one's own (live, authentic, but not faultless) self and to miraculously receive another bodily self instead - one devoid of any shortcomings and weaknesses, but fictional and unrealistic.

This situation provokes a radical transformation of self-consciousness and ethics for the human race as a whole - for example, when the body becomes an object that can easily be refashioned or even changed. Body and gender forfeit their status as basic identification and turn into just one of many possible identifications of the self; they start to depend on social and cultural factors-status, financial freedom, fashion. All these possibilities can cause deformation and loss of selfhood, making one not only highly sensitive but recklessly "omnivorous" and creating various forms of "cultural pathology." Among them is narcissistic perfectionism with its claims to boundlessness, omnipotence, and superiority; disdain of nature with its genuine limitations; belief in the absolute powers of technology; and fetishization of idealistic social, professional, and cultural standards. People with hypochondria, who often seek medical help, have overdependent personality patterns, are suggestible, lack clear internal reference points, and are susceptible to social conformism. They automatically and uncritically "acquire" values, propagated by the media and sociocultural stereotypes, that regard any signs of ageing and imperfection as unacceptable. They turn to "salutary" surgical intervention as if it were able to deliver them from life's problems. They naively believe that after their transformation, with their new looks, they will not encounter cheating, parting, and other disappointments in their lives. They achieve "resolution" of inner conflicts largely through external visible changes because they are childishly "materialist." As a result, their symbolic processing of intrapsychic conflicts is hindered or blocked. Nothing can satisfy or console them except an immediate and desired change in particular "unbearable" circumstances. If they cannot manage to "make" the situation or other people conform to their wishes, 
then the situation is ruined for them; and so an impulsive act becomes the most acceptable way out of an unbearable life crisis - for example, an aesthetic operation can create a narcissistic illusion of an instant glorious future.

\section{Microstructure of Self-Other Representations in Suicidal and Other Self-Destructive Behavior}

Let's examine the specific organization of the representational space of a Narcissus, his affects and cognitive structures, his system of concepts of self and interpersonal relationships (Akhtar, 1984; Kernberg, 2000). According to our research, the poor cognitive differentiation of his representational system, with its inner incongruence and inconsistency and its lack of coherence and integrity, combined with polar affects, is marked by the corresponding parameters of affective-cognitive style. Because of his lack of ability for rational and reflexive self-estimation regardless of actual affective states and frustrations, his self-conception is unstable and exposed to constant fluctuations and distortions. These "swings," typical of borderline and narcissistic personality organization, are swung by his emotional instability and oversensitive self-esteem, by the "grandiosity of the self," along with his inability to conceptualize and symbolize and his predominantly psychosomatic mode of regulation and elimination of psychological traumas (the syndrome of alexithymia).

It is assumed that a consistent, coherent, and noncontradictory representational worldview can develop in childhood and then function stably to defend one from ups and downs; having such a worldview is possible only because of the responsive attitude of a caring adult-that is, only inside a "container" of secure attachments (Bateman \& Fonagy, 2004). Thus, early child-adult relationships serve as a "field" that provides sufficient space for mutual attachment and autonomy (or, on the contrary, provides a "toxic" environment); in this field all the psychic functions are formed, including regulatory systems, cognitive abilities, and language and symbolic means for processing "unbearable" affective states. The "working models of relationships" or the "representational models of object relationships" (terms vary depending on the corresponding theory) acquired in childhood are responsible for the unconscious dispositional ability for specific organization of actual interactions and influence the affective valence ("coloring") of perception, kind or hostile. If 
we put aside the terminological differences, we can easily recognize here some traditional issues of psychological science: the social determinants of development, the role of communication and a child's social inclusion in the culture of human relationships, socialization and its psychological mechanisms as well as the influence of past experience and the individual acquisition of a system of cultural standards that provide a person with a "frame" for building current relationships and making decisions to act in certain ways.

This context guides us in our research on the psychological regularities that determine the disintegration of development, the formation and the functioning of the cognitive structures, and the generalized and schematized concepts of interpersonal (self-other) relationships, which function as a systemically organized adjustment mechanism of social perception. Personality style as a persistent individual pattern consists of three blocks: (1) interactive substructures of perceptive predispositions and schemes that select, predict, and control social activity; (2) defenses and coping mechanisms for affective regulation; and (3) configurations of attitudes toward self and significant others. The integration and interrelation of these substructures determine one's reliance on the settled system of standards in new, difficult, uncertain, or critical situations. If one has lost an ability to wonder or experience emotional inspiration, can't find meaning in these life circumstances, and perceives them exclusively as an anxiety factor, as ambiguity that exceeds the ability to cope with it and threatens a settled and coherent worldview and the continuity of self-identity, then it is most likely that the "answer" to environmental or internal conflict will be expressed in some previously formed (and probably outdated) stereotype of mental response. And yet it is the unconventional situations - especially those in which one discovers the meaning and the finitude of life, the correctness or incorrectness of a chosen path, the commitment of family and friends, the value of one's personality - that give one a choice. They can release the creative potential of the self as well as cause such a powerful "inner earthquake" that violence or suicide may seem the only way out.

We believe that the individual stylistics of a representational system have a major impact on the actual type of communication, determining (and sometimes distorting) social perception and self-image. They also determine the mechanisms for processing frustrations in interpersonal relationships, including loss of a significant other and failures that chal- 
lenge the stability of self-respect. Moreover, the structural and conceptual characteristics of representations of relationships are interconnected and determined by the affective-cognitive style of the personality, which is understood as an individual configuration of affective and cognitive processes, including modes of perception with a varying degree of emotional charge and intra/interpsychic regulatory mechanisms of affective states with a varying degree of psychological differentiation / integrity and of field dependence / autonomy. Thus, there exists an affectivecognitive representational style of self-other relationships - that is, an individual system of concepts of human relationships, their categorization and regulation, with a varying degree of cognitive differentiation, complexity, symbolical mediation, and emotional charge.

This theoretical perspective allows us to view such representations not only as an echo of our past experience of emotional relationships but also as a working model for constructing new experiences of communication, which regulate interiorization, assign algorithms for processing traumatic states in the present and in the future, and eventually determine the degree of tolerance for frustrations in interpersonal relationships. Such modes of affective-cognitive representation of interpersonal interactions are activated in situations of ambiguity and, most important, in break-ups with, separations from, or losses of significant others, and they determine the generalized way of processing the traumatic emotional experience of loss. Thus, tolerance for the emotional experience of loss is assigned by the individual configuration, the individual stylistics, of the whole complex of feelings, fantasies, affects, and self-other representations along with the repertoire of means of rational-reflexive and conceptual processing of this experience, defenses, and coping mechanisms (Sokolova \& Korshunova, 2007; Sokolova \& Sotnikova, 2006b).

\section{The Affective-Cognitive Style as a Predictor of Borderline and Narcissistic Disorders and Behavioral Deviations}

Cognitive field dependence represents excessively concrete thinking, which narrows possibilities beyond the limits of the obvious, the empirical, and the immediate, particularly via reflexive thinking, reconstructive imagination, and dreaming. It hinders anticipation of the future, 
metaphorical reconstruction of the missing and the lost, and thus significantly reduces personal regenerative resources and maintains a state of chronic "emotional hunger," of constant discontent. Low differentiation ("cognitive simplicity," lack of means for analysis and sorting) shows itself in the inability to see subtle differences and changes, to distinguish the essential from the peripheral (especially in the sphere of social relationships and self-perception), and in the "globality" and "dichotomy" of judgments and ideas - in general, the antidialectics of perception.

The excessively high (and, as has been shown, "false") cognitive differentiation of perception is characterized by the excessive specification, "fractionality," mutual incongruence, and fragmentariness of self-other representations; the analytical processes lack impartial reflexivity, consistency, and self-control. But the main defect here is the lack of theoretical synthesis. A relatively high level of cognitive functioning coexists with but is unconnected to intense but poorly verbalized affects; the self-other image is split between devalued and estranged "bad" bodily aspects and idealized, grandiose "good" spiritual aspects. The general configuration of defenses is dominated by the mechanisms of splitting, devaluation, and hypersymbolization with a prevalence of excessively abstract symbols of superiority, uniqueness, and grandiosity, which contribute to rejection and the destruction of relationships with others. The suicidal (and, wider, the parasuicidal, i.e., self-destructive) behavior in these patients is activated in response to narcissistic offences, "collapses" of perfectionist expectations and self-esteem, which are subjectively perceived as a catastrophe, a global, personal failure.

In such a state one loses not only the ability to experience pleasure, to enjoy life, but also the ability to play, to invent, to see the familiar in a new light; one forfeits coherence and consistency of thinking. The analogy with a baby's indifference and delay in cognitive development in response to the prolonged deprivation of maternal love and attention is quite appropriate here (Bowlby, 1973). The absence of the object in reality, uncompensated for by its symbolically supporting representation in the inner world, leads to the irrevocable loss of emotional and social "bonds," cognitive deficit, and loss of the coherence and integrity of mental representations. The worlds inside and outside the self appear in primeval chaos and total ambiguity, out of spatial and temporal dimensions, without any possibility of being expressed in words or of gaining structure and order, a situation that cannot but fill one with confusion 
and overall helplessness. The defense system is forced to function in a simplified mode, to return to a primitive level of cognitive mediation (cognitive simplicity), and sometimes the ability to think and express feelings in words is totally lost. The predominance of splitting over integrity leads to this condition when a traumatic emotional experience, be it a loss of the other or a narcissistic wound, chronically destabilizes the ability to feel and to reflexively process critical states and hinders the preservation of stable personal identity and the maintenance of relationships with significant others (Sokolova \& Korshunova, 2007; Sokolova \& Sotnikova, 2006a).

\section{Affective-Cognitive Style and the Prediction of Psychotherapeutic Effectiveness}

People with borderline and narcissistic personality organization belong to the group of "difficult" patients, those resistant to any type of medication and psychological help because of their unrealistically maximalist demands and expectations of immediate, magical healing. But help in finding individual zones of difficulty as well as zones of proximal development - the perspectives of psychotherapy - comes from a differentiated approach based on consideration of subtle individual differences and personal stylistics. Thus, patients with low cognitive differentiation and high field dependence show high compliance, but this compliance is accompanied by intellectual passivity, difficulties in analyzing and reframing, and their typical literalness. These characteristics limit their ability to feel relief and at least partial satisfaction from words and mental transformations rather than from real acts or "things." In a sense, such patients are too "materialist." They are yearning for visual, concrete, and "real" changes in life; relativities and "artificialities" do not console them, but a therapist cannot "give" them more.

Overautonomous and overdifferentiated patients pose for a therapist another type of challenge. In psychotherapy they are prone to demonstrate various and ingenious forms of resistance; they sabotage cooperative relationships, break therapeutic contracts, block placebo effects. Because of their panic and fear of "absorption" by a "powerful" therapist, such patients are inclined to suddenly reject and interrupt treatment under the slightest threat that their lack of self-sufficiency may be "unmasked." 
As we can see, both types of patients suffer from a failure of "containment" (Bion, 1962) and from difficulties in accepting and "interiorizing" as provided by therapist emotional support and cognitive means for processing and integrating traumatic experience. But, although they are complex and systemic, the psychological mechanisms that cause the risk that psychotherapy will have low effectiveness are different. Fielddependent patients "fail" because of their inability to generalize and cognitively integrate experience, their excessive need to rely on external sources of influence (the therapist), and their lack of inner resources. On the contrary, overautonomous patients show understanding and seem to be capable of cognitive integration, but, because of their rejection of emotional bonds and cooperative relationships through their basic mistrust for the other, they are unable to "accept," withhold, and maintain achieved positive changes. Obviously, the prognosis is more favorable when traumatic feelings are available for sharing with the therapist as a significant other and when therapeutic relationships reconstruct some lost emotional bonds, develop processes of symbolization, imagination, signification, and expressive verbalization; as a result, "unspeakable" traumatic states are "contained" cognitively and emotionally. "Words," notes MacDougall, "are invaluable containers" (2007, p. 86). Psychotherapeutic "containment" serves integration and the acquisition of noncontradictory unification of emotional attitude and mental representation, of "gathering oneself" into a coherent, meaningful, and consistent self-identity based on human bonds and maintained despite the vicissitudes of life experience. Unfortunately, cognitive or (and) emotional deficit may become a provocative psychological mechanism of generalized resistance to treatment (Blatt, 1990, Blatt \& Lerner, 1983; Sokolova, 2002 , 2009). The problem is that the transitory space of "play," "dream," and relativity that is created in therapy by compassionate words is hardly shared by such patients. In a certain sense, they are too materialist and nonidealist; they crave visible and "real" changes in life, and the relativity and "artificiality" of substitutions do not console them.

\section{Conclusion and Perspectives on Research}

In seems that the impossibility of formulating a unified theoretical and exploratory paradigm is caused by the essentially partial character of most studies, which focus on particular traits of personal style outside 
their systemic interrelations. There is also a considerable gap between the epistemologies of the humanities and the natural sciences, which significantly narrows the possibilities for interpreting data acquired through different scientific approaches and methods-differences that are sometimes mutually unacknowledged.

Our meta-analysis as well as many years of research on the systemic mechanisms of destabilization of self-identity allow us to claim that the affective-cognitive style is one of the socio-cognitive mechanisms of functional and structural distortion of self-identity and is a predictor of risk for the development of borderline and narcissistic personality disorders along with the comorbid diseases - chronic neuroses, affective pathology, hypochondria, food addiction, suicide - and other types of self-destructive behavior in people with high victimhood because of insufficiently defined and blurred borders of the self that are consequently accessible to intrusion and violation.

\section{References}

Adorno, T.W., Frenkel-Brunswik, E., Levinson, D.J., \& Sanford, R.N. (1950). The authoritarian personality. New York: Harper and Row.

Akhtar, S. (1984). Identity diffusion syndrome. American Journal of Psychiatry, 141(11), 1381-1384.

Bateman A., \& Fonagy, P. (2004). Psychotherapy for borderline personality disorder. New York: Oxford University Press Inc.

Bion, W. (1962). A theory of thinking. International Journal of Psychoanalysis, 43, 306-310.

Blatt, S. (1990). The Rorschach A test of perception or an evaluation representation. Journal of Personality Assessment, 55, 394-416.

Blatt, S., \& Lerner, H. (1983). The psychological assessment of object representation. Journal of Personality Assessment, 47, 7-28.

Bowlby, J. (1973). Attachment and loss. Vol. 2. Separation: anxiety and anger. New York: Basic Books (reissued 1999).

Chuprikova, N.I. (2007). Umstvennoe razvitie: Princip differenciacii [Mental development: Differentiation principle]. St. Petersburg: Piter.

Elizur, A. (1949). Content analysis of the Rorschach with regard to anxiety and hostility. Rorschach Research Exchange, 13, 247-284.

Fischer S., \& Cleveland, S.E. (1968). Body image and personality. New York: Dover Press. 
Hartmann, H. (1951). Ego psychology and problem of adaptation. New York: International Universities Press.

Kernberg, O. (2000). Otnosheniya lyubvi: Norma i patologiya [Love relations: Normality and pathology]. Moscow: Klass.

Katko, N.J., Gregory, J., Meyer, G.J., Mihura, G., \& Bombel, G. (2009). The Interrater Reliability of Elizur's Hostility Systems and Holt's Aggression Variables: A MetaAnalytical Review. Journal of Personality Assessment, 91, Issue 4, 357-364.

Levin, K. (1935). A dynamic theory of personality. New York: McGraw-Hill.

MacDougall, J. (2007). Teatry tela [The theaters of the body]. Moscow: CogitoCenter.

Marty, P., \& M'Uzan, M. de (2000). Operativnoe myshlenie [Operational thinking]. In A. Rossohin (Ed.), Antologiya sovremennogo psihoanaliza [Anthology of modern psychoanalysis] (pp. 327-336). Moscow: Institut Psihologii RAN.

Rapaport, D. (1951). Organization and pathology of thought. New York: McGrawHill.

Sokolova, E.T. (1976). Motivaciya i vosprijatie v norme i patologii [Normal and pathological motivation and perception]. Moscow: Moscow State University.

Sokolova, E.T. (1989). Samosoznanie i samoocenka pri anomaliyah lichnosti [Selfconsciousness and self-esteem in abnormalities of personality]. Moscow: Moscow State University.

Sokolova, E.T. (1995). Osobennosti lichnosti pri pogranichnyh rasstrojstvah [Personality traits in borderline disorders]. In E.T. Sokolova \& V.V. Nikolaeva, Osobennosti lichnosti pri pogranichnyh rasstrojstvah lichnosti i somaticheskih zabolevaniyah [Personality traits in borderline personality disorders and somatic illnesses] (pp. 27-206). Moscow: Argus.

Sokolova, E.T. (2002, reissued 2005, 2007, 2010). Psihoterapiya: Teoriya i praktika [Psychotherapy: Theory and practice]. Moscow: Academia.

Sokolova, E.T. (2009). Narcissism kak klinicheskij i socio-kulturnyj fenomen [Narcissism as a clinical and sociocultural phenomenon]. Voprosy Psihologii [Psychology Issues], 1, 67-80.

Sokolova, E.T., Burlakova, N.S., \& Leontiu, F. (2001). K izucheniju "diffuznoj” gendernoj identichnosti pri pogranichnoj lichnostnoj organizacii: Teoreticheskij analiz problemy [On "diffuse" gender identity in borderline personality organization: Theoretical analysis of the issue]. Voprosy Psyhologii [Psychology Issues], 6, 6-17.

Sokolova, E.T., Burlakova, N.S., \& Leontiu, F. (2002). Svjaz' fenomena diffusnoj gendernoj identichnosti s kognitivnym stilem lichnosti [Relationship of the phenomenon of diffuse gender identity to personal cognitive style]. Voprosy Psyhologii [Psychology Issues], 3, 41-51. 
Sokolova, E.T., \& Iljina, S.V. (2000). Rol' emocional'nogo opyta nasiliya dlya samoidentichnosti zhenschin, zanimayuschihsya prostituciyej [The role of the emotional experience of violence in the self-identity of women engaged in prostitution]. Psihologicheskij Zhurnal [Psychological Journal], 21(5), 70-81.

Sokolova, E.T., \& Korshunova, A.R. (2007). Affektivno-kognitivnyj stil' reprezentacii otnoshenij ja-drugoj u lic s suicidalnym povedeniem [Affective-cognitive style of representation of self-other relationships in people with suicidal behavior]. Vestnik Moskovskogo Universiteta [Moscow University Bulletin], Ser. 14, Psychology, 4, 48-63.

Sokolova, E.T., \& Sotnikova, Y. (2006a). Problema suicyda: Kliniko-psihologicheskiy rakurs [The phenomenon of suicide: Clinical perspective]. Voprosy Psihologii [Psychology Issues], 2, 103-115.

Sokolova, E.T., \& Sotnikova, Y. (2006b). Svyaz' psihologicheskih mehanizmov zaschity s affectivno-kognitivnym stilem lichnosti [Relation of psychological defense mechanisms to the affective-cognitive style of personality]. Vestnik Moskovskogo Universiteta [Moscow University Bulletin], Ser. 14, Psychology, 2, 12-23.

Urist, J. (1977). The Rorschach test and the assessment of object relations. Journal of Personality Assessment, 41, 3-9.

Vygotsky, L.S. (1956). Izbrannye psihologicheskie issledovaniya [Selected psychological studies] (Ed. by A.N. Leontiev, \& A.R. Luria). Moscow: Academy of pedagogical science RSFSR.

Vygotsky, L.S. (1982). Sobranie sochineniy [Collected works], in 6 volumes. Vol. 1 (Ed. by A.R. Luria, \& M.G. Yaroschevsky). Moscow: Pedagogika.

Vygotsky, L.S. (1983). Sobranie sochineniy [Collected works], in 6 volumes. Vol. 5 (Ed. by T.A. Vlasova). Moscow: Pedagogika.

Werner, H., \& Kaplan, B. (1963). Symbol formation: An organismic developmental approach to language and the expression of thought. New York: John Wiley.

Westen, D. (1990). Object relations and social cognition in borderlines, major depressives, and normals: A Thematic Apperception Test analysis. Journal of Consulting and Clinical Psychology, 2, 355-364.

Witkin, H.A., Lewis, H.B., et al. (1954). Personality through perception: An experimental and clinical study. Oxford, UK.

Witkin, H.A., \& Goodenough, D.R. (1981). Cognitive styles - essence and orgins: Field dependence and field independence. New York: International Universities. 